\title{
Alterations in the Baroreceptor Reflex in Conscious Dogs with Heart Failure
}

\author{
Charles B. Higgins, Stephen F. Vatner, Dwain L. Eckberg, and \\ Eugene Braunwald \\ From the Department of Medicine, University of California, San Diego, \\ School of Medicine, La Jolla, California 92037
}

\begin{abstract}
A B S T R A C T The effectiveness of the baroreceptor reflex in conscious dogs with experimental cardiac hypertrophy and heart failure was compared with that in a group of normal conscious dogs. Cardiac hypertrophy and heart failure were produced by tricuspid avulsion and progressive pulmonary stenosis. The sensitivity of the baroreceptor reflex to transient hypertension was assessed by determining the slope of the regression line relating the prolongation of the $R-R$ interval to the rise in systolic arterial pressure during the transient elevation of arterial pressure induced by an intravenous injection of 1-phenylephrine. The mean slope averaged $22.4 \pm 2.3 \mathrm{msec} / \mathrm{mm} \mathrm{Hg}$ in 16 normal animals, $23.1 \pm 1.5$ in five sham-operated animals, and was significantly reduced to $8.3 \pm 0.8$ in 10 dogs with hypertrophy alone $(P<0.001)$, and to $3.3 \pm 0.5$ in nine dogs with heart failure $(P<0.001)$. The response to baroreceptor hypotension was compared during bilateral carotid artery occlusion (BCO) in six normal and six heart failure dogs previously instrumented with Doppler flow transducers on the superior mesenteric and renal arteries. During BCO, in normal dogs arterial pressure increased $52 \pm 4 \mathrm{~mm}$ $\mathrm{Hg}$, heart rate $33 \pm 2$ beats/min, mesenteric resistance $0.17 \pm 0.03 \mathrm{~mm} \mathrm{Hg} / \mathrm{ml}$ per $\mathrm{min}$, and renal resistance 0.37 $\pm 0.10 \mathrm{~mm} \mathrm{Hg} / \mathrm{ml}$ per min. In the heart failure group all of these variables increased significantly less $(P<0.01)$; arterial pressure rose $25 \pm 3 \mathrm{~mm} \mathrm{Hg}$, heart rate $13 \pm 4$ beats/min, mesenteric resistance $0.04 \pm 0.007 \mathrm{~mm} \mathrm{Hg}$ / $\mathrm{ml}$ per $\mathrm{min}$, and renal resistance $0.18 \pm 0.09 \mathrm{~mm} \mathrm{Hg}$ / $\mathrm{ml}$ per min.
\end{abstract}

This work was presented in part at the National Meeting of the American Federation for Clinical Research, Atlantic City, N. J., 1 May 1971. Clin. Res. 19: 321.

Dr. Higgins is a Surgical Scholar supported by U. S. Public Health Service Grant GM 01559.

Received for publication 28 July 1971 and in revised form 28 October 1971.
Thus, in heart failure, all measured systemic and regional circulatory adjustments consequent to baroreceptor hypo- and hypertension are markedly attenuated. This study demonstrates a profound derangement of a major cardiovascular control mechanism in experimental heart failure.

\section{INTRODUCTION}

The baroreceptor reflex is recognized as one of the major homeostatic mechanisms promoting stability of the circulation during sudden alterations in arterial blood pressure. When the pressor receptors sense a decrease in arterial pressure, this reflex causes tachycardia (1-3), an elevated inotropic state $(1,4,5)$, and peripheral vasoconstriction $(1,6,7)$, while an increase in pressure results in directionally opposite effects (1-5, $8,9)$. Since each of these effects tends to return arterial pressure to normal, this reflex has been considered to be a major compensatory mechanism in maintaining the circulation during periods of circulatory stress (1). In states of low cardiac output, including heart failure, the increase in adrenergic activity brought about by this reflex is thought to compensate in part for the low output state $(1,10)$. However, the sensitivity of the baroreceptor reflex system to alterations in arterial pressure in chronic low output states has not been assessed. In order to study the sensitivity of this reflex in heart failure, we compared some of the systemic and regional hemodynamic effects of induced baroreceptor hyper- and hypotension in normal healthy dogs and in dogs with experimentally produced cardiac hypertrophy and heart failure. Since the sensitivity of this reflex is known to be affected profoundly by the level of consciousness $(11,12)$ and by various anesthetic agents $(12,13)$, this study was conducted in the conscious unsedated dog. 


\section{METHODS}

16 adult mongrel dogs weighing between 22 and $31 \mathrm{~kg}$ underwent a two-stage surgical procedure for the production of congestive heart failure by a modification of the technique described by Barger, Roe, and Richardson (14). Using general anesthesia (pentobarbital $\mathrm{Na}, 25 \mathrm{mg} / \mathrm{kg}$ ) and sterile surgical technique, the tricuspid valve was avulsed and a pneumatic cuff placed around the main pulmonary artery. Postoperatively, the pneumatic cuff was inflated with saline in $1.0 \mathrm{ml}$ increments on two occasions producing progressive pulmonary stenosis which resulted in the development of cardiac hypertrophy alone in seven animals and hypertrophy followed by failure in nine animals after further inflation with $0.2-0.6 \mathrm{cc}$ saline. Three of the nine animals which eventually developed heart failure were evaluated in the hypertrophy state before further inflation of the pneumatic cuff to produce heart failure. Thus, over-all, there were 10 dogs comprising the hypertrophy group and 9 the failure group. Heart failure in the latter group was characterized by ascites, elevated right ventricular systolic and end diastolic pressures, increase in the ratio of right ventricular to left ventricular mid-free-wall thickness, markedly depleted right ventricular norepinephrine stores, but normal arterial blood gases (Table I). Two-stage sham operations consisting of a right atriotomy and dissection around but without constriction of the main pulmonary artery were performed in an additional five dogs.

Doppler ultrasonic flow probes were implanted around the superior mesenteric and left renal arteries and catheters filled with heparin were placed in the central aorta through either a lumbar artery or a branch of the right femoral artery in six normal dogs and six dogs with heart failure. Pneumatic cuffs were placed around both common carotid arteries in the six normal, six heart failure, and four shamoperated animals. At the time of operation the precise amount of saline injectate required for complete occlusion of the carotid arteries was determined and during terminal experiments this was confirmed by direct vision and palpation of the artery. In addition, at the time of the terminal experiment, measurements were made of the arterial pressure distal to the cuff during occlusion by a catheter placed in the lingual artery and advanced to the area of the carotid sinus.

The experiments were conducted 2-5 wk after operation in normal dogs and at least 2 months after thoracotomy in the animals with hypertrophy and heart failure and in the sham-operated dogs. In the first part of the study, the baroreceptor reflex response to transient hypertension was determined in normal dogs, in sham-operated dogs, and in dogs with cardiac hypertrophy with and without overt heart failure by the method of Smyth, Sleight, and Pickering (11). Three animals were evaluated on three separate occasions: in the normal state, in the hypertrophy state, and in the heart failure state. Five dogs were studied in the normal and hypertrophy states and another two animals were studied in the normal and heart failure states. The systolic arterial pressure (SAP) ${ }^{1}$ of successive pulses was plotted against the R-R interval of the next beat during the transient rise in arterial pressure produced by the bolus intravenous injection of 1 -phenylephrine $(4-40 \mu \mathrm{g} / \mathrm{kg})$. The dose of 1-phenylephrine used in each experiment was that necessary to raise SAP approximately $50 \mathrm{~mm} \mathrm{Hg}$, and the mean rise in SAP was comparable among various experimental groups. The slope of the regression line for SAP plotted against the $R-R$ interval was used as a quantitative measure of baroreceptor reflex sensitivity. The slopes were computed using the least squares technique (15) and expressed as the prolongation of the $R-R$ interval in milliseconds per millimeter $\mathrm{Hg}$ elevation of SAP $(\Delta \mathrm{R}-\mathrm{R} /$ $\triangle \mathrm{SAP})$. The correlation coefficients expressing the nearness of the linear relationship between $\Delta \mathrm{SAP}$ and $\Delta \mathrm{R}-\mathrm{R}$ for each observation in each dog were calculated by standard regression analysis (16). Differences in the mean slopes of each group were tested for statistical significance by the group $t$ test (15).

In the second part of the study, the responsiveness of the carotid sinus baroreceptor reflex to induced hypotension was compared in six normal and in six dogs with heart failure by comparing the alterations in mean arterial pressure, instantaneous heart rate, and regional flows and resistances during short periods of bilateral common carotid artery occlusion (BCO). During BCO arterial pressure distal to the occluding cuff, i.e. in the area of the carotid sinus, decreased by an average of $40 \mathrm{~mm} \mathrm{Hg}$ initially and $32 \mathrm{~mm}$ $\mathrm{Hg}$ during the steady-state period in the normal animals, and by $45 \mathrm{~mm} \mathrm{Hg}$ and $38 \mathrm{~mm} \mathrm{Hg}$ in the animals with heart failure.

Blood flow in the regional beds was determined as the product of the velocity of flow measured by the Doppler ultrasonic flowmeter $(17,18)$ and the cross-sectional area of the vessel measured at autopsy. The cross-sectional area of the blood vessel at autopsy can be expected to vary from that during life, suggesting caution in interpreting the absolute values for volume flow. Velocity, as measured by the Doppler flowmeter, is linearly related to volume flow as long

${ }^{1}$ Abbreviations used in this paper: $\mathrm{BCO}$, bilateral carotid artery occlusion; SAP, systolic arterial pressure.

TABLE I

Characterization of Experimental Cardiac Hypertrophy and Heart Failure States

\begin{tabular}{lccc}
\hline & Normals & Hypertrophy & Heart failure \\
\hline Ascites & $0 / 16$ & $0 / 7$ & $9 / 9$ \\
$\mathrm{RV} / \mathrm{LV}$ mid-free-wall thickness & $0.35 \pm 0.04$ & $0.74 \pm 0.11$ & $0.82 \pm 0.06$ \\
$\mathrm{RV}$ norepinephrine concentration $(\mu \mathrm{g} / \mathrm{g}$ heart) & $0.69 \pm 0.07$ & - & $0.05 \pm 0.01$ \\
$\mathrm{RV}$ peak systolic pressure $(\mathrm{mm} \mathrm{Hg})$ & $24 \pm 4$ & $35 \pm 6$ & $74 \pm 8$ \\
$\mathrm{RV}$ end diastolic pressure $(\mathrm{mm} \mathrm{Hg})$ & $4.7 \pm 1.0$ & $5.2 \pm 0.9$ & $15.4 \pm 2.1$ \\
Arterial $\mathrm{Po}_{2}(\mathrm{~mm} \mathrm{Hg})$ & $86.6 \pm 2.9$ & - & $85.1 \pm 4.1$ \\
Arterial $\mathrm{PcO}_{2}(\mathrm{~mm} \mathrm{Hg})$ & $34.2 \pm 2.3$ & - & $38.1 \pm 3.3$ \\
Arterial $\mathrm{pH}$ & $7.43 \pm 0.01$ & - & $7.45 \pm 0.03$ \\
\end{tabular}

$R V$, right ventricle; $L V$, left ventricle. 
as the cross-sectional area within the transducer does not vary. At autopsy, the vessel walls were intimately adherent to the transducer by a fibrous shell, minimizing changes in cross-sectional area with alterations in arterial pressure. Furthermore, volume calibrations conducted in our laboratory by timed collections of blood flow with beaker and stopwatch have verified the accuracy and linearity of the flowmeter (18). Zero flow was repeatedly determined electrically and confirmed terminally by mechanical occlusion of the vessel. A prior study from our laboratory has demonstrated repeatedly and consistently the accuracy and constancy of electrical zero with the Doppler flowmeter (18). Arterial pressure was sensed by the catheter previously placed in the central aorta and measured with a Statham $\mathrm{P} 23 \mathrm{Db}$ strain gauge manometer (Statham Instruments, Inc., Los Angeles, Calif.).

Mean arterial pressure and mean blood flows were derived by $\mathrm{RC}$ electronic filters with a $2 \mathrm{sec}$ time constant. A cardiotachometer (Beckman type 9857, Beckman Instruments, Inc., Fullerton, Calif.), triggered by the electrical signal from the arterial pressure pulse, provided instantaneous and continuous records of heart rate. Data were recorded on a multichannel oscillograph and magnetic tape recorder. Mean regional resistances were calculated as the quotient of mean arterial pressure and mean regional blood flows.

\section{RESULTS}

\section{Baroreceptor hypertension}

The mean slope for the group of normal animals which averaged $22.4 \pm 2.3$ ( $\mathrm{sEM}$ ) $\mathrm{msec} / \mathrm{mm} \mathrm{Hg}$ was essentially

\section{BARORECEPTOR HYPERTENSION}

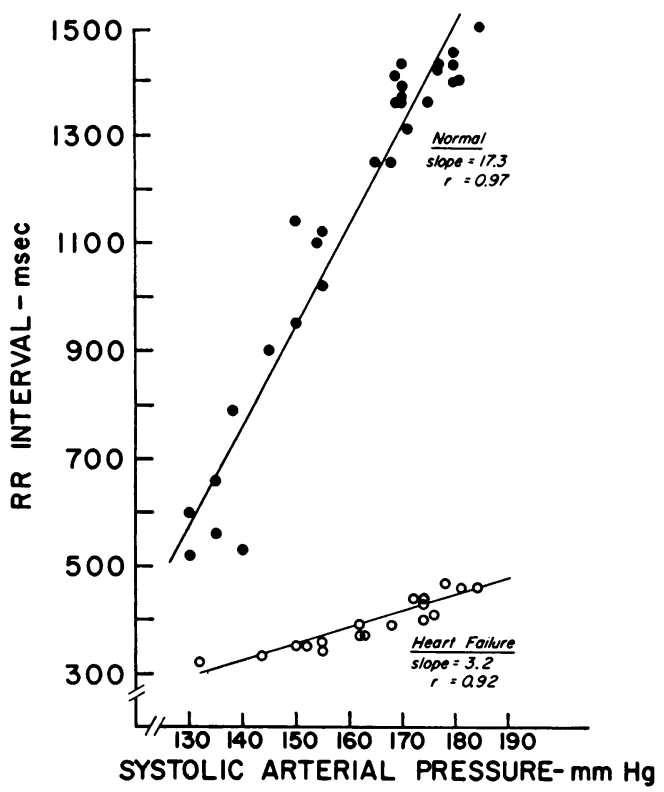

FIGURE 1 Baroreceptor hypertension. Each systolic arterial pressure is plotted against the following $R-R$ interval during the transient rise in arterial pressure induced by a bolus intravenous injection of 1-phenylephrine in the same dog in the normal state (closed circles) and in the heart failure state (open circles). There is a marked depression in the slope of the regression line in the heart failure state compared to the slope existing in the normal state.
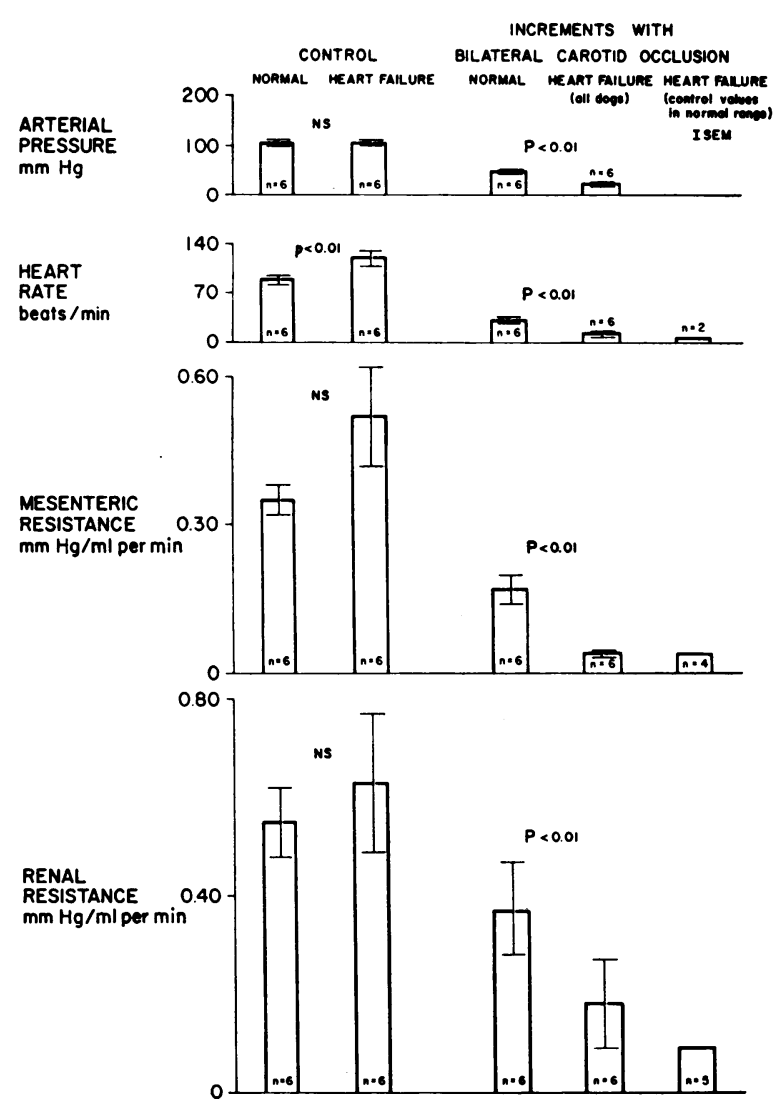

FIGURE 2 Control values for each of the variables in the normal and heart failure groups are shown on the left and the increments in each variable during bilateral carotid occlusion in the normal and heart failure groups, and the heart failure group with control values in the normal range are shown on the right.

identical in the sham-operated animals, $23.1 \pm 1.5$, and was significantly depressed $(P<0.001)$ in the group with cardiac hypertrophy, $8.3 \pm 0.8$, and with overt heart failure, $3.3 \pm 0.5$ (Table II). The hypertrophy group, with presumably less severe cardiac overload, had less reduction of sensitivity than the group with overt heart failure $(P<0.01)$. In Fig. 1 , the profoundly depressed baroreceptor sensitivity determined in the heart failure state is compared with the normal sensitivity displayed by the same dog before the production of heart failure. A similar depression in sensitivity was observed in each animal studied in the normal state and after either hypertrophy or heart failure had developed (Table II).

\section{Baroreceptor hypotension}

Mean arterial pressure. Base line levels were similar in normal and heart failure animals (Table III) ; however, the peak increments in arterial pressure with $\mathrm{BCO}$ were lower in the heart failure group in which they averaged only $25 \pm 3 \mathrm{~mm} \mathrm{Hg}$, compared to $52 \pm 4 \mathrm{~mm}$ 
TABLE II

Individual Slopes and Correlation Coefficients Determined

\begin{tabular}{|c|c|c|c|c|c|c|c|c|}
\hline \multirow[b]{2}{*}{$\begin{array}{l}\text { Dog } \\
\text { No. }\end{array}$} & \multicolumn{4}{|c|}{ Normals } & \multicolumn{4}{|c|}{ Sham } \\
\hline & $\begin{array}{l}\text { Heart } \\
\text { rate }\end{array}$ & $\begin{array}{l}\text { Mean } \\
\text { arterial } \\
\text { pressure }\end{array}$ & Slope & $\begin{array}{l}\text { Correlation } \\
\text { coefficient }\end{array}$ & $\begin{array}{l}\text { Heart } \\
\text { rate }\end{array}$ & $\begin{array}{l}\text { Mean } \\
\text { arterial } \\
\text { pressure }\end{array}$ & Slope & $\begin{array}{l}\text { Correlation } \\
\text { coefficient }\end{array}$ \\
\hline & & & $\begin{array}{c}\text { msecR-R/ } \\
m m \text { HgSAP }\end{array}$ & & beats/min & $m m \mathrm{Hg}$ & $\begin{array}{c}m s e c R-R / \\
m m \mathrm{HgSAP}\end{array}$ & \\
\hline 1 & 111 & 125 & 49.5 & 0.94 & - & - & - & - \\
\hline 2 & 80 & 112 & 21.9 & 0.95 & - & - & - & - \\
\hline 3 & 85 & 125 & 17.5 & 0.89 & - & - & - & - \\
\hline 4 & 139 & 128 & 8.5 & 0.91 & - & - & - & - \\
\hline 5 & 100 & 85 & 21.7 & 0.96 & - & - & - & - \\
\hline 6 & 125 & 70 & 17.3 & 0.97 & - & - & - & - \\
\hline 7 & 133 & 106 & 18.7 & 0.69 & - & - & - & - \\
\hline 8 & 92 & 126 & 19.7 & 0.88 & - & - & - & - \\
\hline 9 & 95 & 84 & 33.6 & 0.90 & - & - & - & - \\
\hline 10 & 133 & 100 & 18.7 & 0.89 & - & - & - & - \\
\hline 11 & 133 & 100 & 26.2 & 0.93 & - & - & - & - \\
\hline 12 & 111 & 100 & 22.8 & 0.94 & - & - & - & - \\
\hline 13 & 91 & 106 & 24.6 & 0.96 & - & - & - & - \\
\hline 14 & 95 & 102 & 17.4 & 0.93 & - & - & - & - \\
\hline 15 & 102 & 90 & 24.4 & 0.93 & - & - & - & - \\
\hline 16 & 88 & 115 & 16.3 & 0.75 & - & - & - & - \\
\hline 17 & - & - & - & - & 133 & 100 & 26.2 & 0.93 \\
\hline 18 & - & - & - & - & 111 & 100 & 22.8 & 0.94 \\
\hline 19 & - & 一 & - & - & 91 & 106 & 24.6 & 0.96 \\
\hline 20 & - & - & - & - & 95 & 102 & 17.4 & 0.93 \\
\hline 21 & - & - & - & - & 102 & 90 & 24.4 & 0.93 \\
\hline 22 & 一 & 一 & - & - & - & - & - & - \\
\hline 23 & - & - & - & - & - & - & - & - \\
\hline 24 & - & - & - & - & - & - & - & - \\
\hline 25 & - & - & - & - & - & - & - & - \\
\hline 26 & - & - & - & - & - & - & - & - \\
\hline 27 & - & - & - & - & - & - & - & - \\
\hline Mean \pm SEM & $107 \pm 5$ & $105 \pm 4$ & $22.4 \pm 2.3$ & & $106 \pm 7$ & $100 \pm 2$ & $23.1 \pm 1.5$ & \\
\hline
\end{tabular}

$\mathrm{Hg}$ in the normal animals $(P<0.01)$ (Fig. 2). Thus, the absolute levels of peak mean arterial pressure achieved were significantly lower in the animals with heart failure $(133 \pm 6 \mathrm{~mm} \mathrm{Hg})$ than in the normal dogs $(153 \pm 1 \mathrm{~mm} \mathrm{Hg})(P<0.01)$. The elevation in arterial pressure during $\mathrm{BCO}$ in sham-operated animals was nearly identical to that in the normal dogs (Table III).

Heart rate. The animals with heart failure had a significantly higher base line heart rate than the normal dogs $(125 \pm 11$ beats $/ \mathrm{min}$ vs. $88 \pm 8$ beats $/ \mathrm{min})$ $(P<0.01)$ (Table III). However, their increment in heart rate with $\mathrm{BCO}$ was significantly reduced, averaging $13 \pm 4$ beats $/ \mathrm{min}$ compared to the normal of $31 \pm 2$ beats $/ \min (P<0.01)$ (Fig. 2$)$. These reduced increments do not appear to be due to the higher average base line level, since the two animals with heart failure whose base line rates were within the normal range (dogs Nos. 3 and 6, with heart rates of 93 and
102 beats/min, respectively) exhibited very small increments in rate with BCO (6 beats/min) (Fig. 2). The response in heart rate during $\mathrm{BCO}$ in sham-operated animals was nearly identical to that observed in the normal dogs (Table III).

Mesenteric resistance. Mean mesenteric resistance during the base line period tended to be higher in the dogs with heart failure $(0.52 \pm 0.10 \mathrm{~mm} \mathrm{Hg} / \mathrm{ml}$ per $\mathrm{min})$ compared to that in the normal dogs $(0.35 \pm 0.03$ $\mathrm{mm} \mathrm{Hg} / \mathrm{ml}$ per $\mathrm{min}$ ) but this difference was not statistically significant $(0.05<P<0.1)$. During BCO it rose far less in the heart failure group $(0.045 \pm 0.007$ $\mathrm{mm} \mathrm{Hg} / \mathrm{ml}$ per $\mathrm{min})$ than in the normal animals $(0.17$ $\pm 0.03 \mathrm{~mm} \mathrm{Hg} / \mathrm{ml}$ per $\min )(P<0.01)$ (Fig. 2 , Table III). This significantly smaller increase in resistance with $\mathrm{BCO}$ was also evident in the four dogs with heart failure whose base line levels of mesenteric vascular resistance were within the normal range, i.e., $<0.49$ $\mathrm{mm} \mathrm{Hg} / \mathrm{ml}$ per min. In this subgroup, mesenteric resist- 
during the Rise in Arterial Pressure Induced by 1-Phenylephrine

\begin{tabular}{|c|c|c|c|c|c|c|c|}
\hline \multicolumn{4}{|c|}{ Hypertrophy } & \multicolumn{4}{|c|}{ Failure } \\
\hline $\begin{array}{l}\text { Heart } \\
\text { rate }\end{array}$ & $\begin{array}{c}\text { Mean } \\
\text { arterial } \\
\text { pressure }\end{array}$ & Slope & $\begin{array}{l}\text { Correlation } \\
\text { coefficient }\end{array}$ & $\begin{array}{l}\text { Heart } \\
\text { rate }\end{array}$ & $\begin{array}{c}\text { Mean } \\
\text { arterial } \\
\text { pressure }\end{array}$ & Slope & $\begin{array}{l}\text { Correlation } \\
\text { coefficient }\end{array}$ \\
\hline beats/min & $m m \mathrm{Hg}$ & $\begin{array}{c}m s e c R-R / \\
m m \mathrm{HgSAP}\end{array}$ & & beats/min & $m m \mathrm{Hg}$ & $\begin{array}{c}m s e c R-R / \\
m m \mathrm{HgSAP}\end{array}$ & \\
\hline 111 & 115 & 7.86 & 0.77 & 121 & 100 & 2.7 & 0.89 \\
\hline 95 & 129 & 7.4 & 0.83 & - & - & - & - \\
\hline 150 & 95 & 8.0 & 0.90 & 162 & 88 & 0.7 & 0.71 \\
\hline 一 & - & - & - & 159 & 142 & 6.0 & 0.92 \\
\hline 92 & 125 & 14.1 & 0.83 & - & - & - & - \\
\hline - & - & - & - & 127 & 82 & 3.4 & 0.95 \\
\hline 171 & 96 & 4.8 & 0.93 & 一 & - & - & - \\
\hline 143 & 132 & 8.1 & 0.95 & - & - & - & - \\
\hline 111 & 94 & 8.6 & 0.81 & 120 & 92 & 1.8 & 0.69 \\
\hline 162 & 110 & 8.5 & 0.93 & - & - & - & - \\
\hline- & - & - & - & - & - & - & - \\
\hline - & - & - & - & - & - & - & - \\
\hline - & - & - & - & - & - & - & - \\
\hline 一 & - & - & - & - & - & - & - \\
\hline - & - & - & - & - & - & - & - \\
\hline - & - & - & - & - & - & - & - \\
\hline - & - & - & - & - & - & - & - \\
\hline - & - & - & - & - & - & - & - \\
\hline - & - & - & - & 一 & - & - & - \\
\hline - & - & - & - & - & - & - & - \\
\hline- & - & - & - & - & - & - & - \\
\hline 180 & 93 & 6.6 & 0.90 & - & - & - & - \\
\hline 143 & 118 & 10.3 & 0.95 & - & - & - & - \\
\hline- & - & - & - & 100 & 127 & 3.1 & 0.76 \\
\hline - & - & - & - & 167 & 80 & 4.4 & 0.96 \\
\hline - & - & - & - & 166 & 125 & 5.0 & 0.97 \\
\hline - & - & - & - & 146 & 95 & 2.8 & 0.99 \\
\hline $136 \pm 10$ & $110 \pm 5$ & $8.3 \pm 0.8$ & & $137 \pm 8$ & $103 \pm 7$ & $3.3 \pm 0.8$ & \\
\hline
\end{tabular}

ance rose by an average of only $0.04 \mathrm{~mm} \mathrm{Hg} / \mathrm{ml}$ per min, a value which was also significantly lower than in the normal dogs $(P<0.01)$.

The time course of the effects of a prolonged period of $\mathrm{BCO}$ on mesenteric hemodynamics in the normal state and later in the same dog in the heart failure state is shown in Fig. 3.

Renal resistance. The base line levels of mean renal vascular resistance were similar in normal $(0.55 \pm 0.07)$ and heart failure dogs $(0.63 \pm 0.14)(P>0.3)$. With $\mathrm{BCO}$, resistance rose significantly less in the heart failure group $(0.18 \pm 0.09 \mathrm{~mm} \mathrm{Hg} / \mathrm{ml}$ per $\mathrm{min})$ than in the normal animals $(0.37 \pm 0.10)(P<0.01)$ (Fig. 2, Table III). This difference persisted when only the five heart failure animals whose control levels of renal resistance were within the normal range (i.e., $<0.84 \mathrm{~mm}$ $\mathrm{Hg} / \mathrm{ml}$ per min) were considered.

\section{DISCUSSION}

In the conscious dogs with cardiac hypertrophy or failure the responsiveness of the baroreceptor reflex arc to hypertension, as assessed by the prolongation of the $R-R$ interval, is markedly attenuated. Recently, a profound depression of this reflex has been observed also in patients with heart disease of diverse etiologies (19). The observation in the present study that the animals with hypertrophy but without overt heart failure had less reduction of sensitivity than the group with overt heart failure suggests that the severity of this dysfunction of the baroreceptor reflex arc may be a function of the severity of the cardiac abnormality. Apparently, the sensitivity of this reflex is altered under other circumstances as well, since it has been shown to be accentuated during natural sleep (11) and depressed in hypertension in experimental animals (20) and man (21) and during anesthesia (13) and exercise $(22,23)$ 


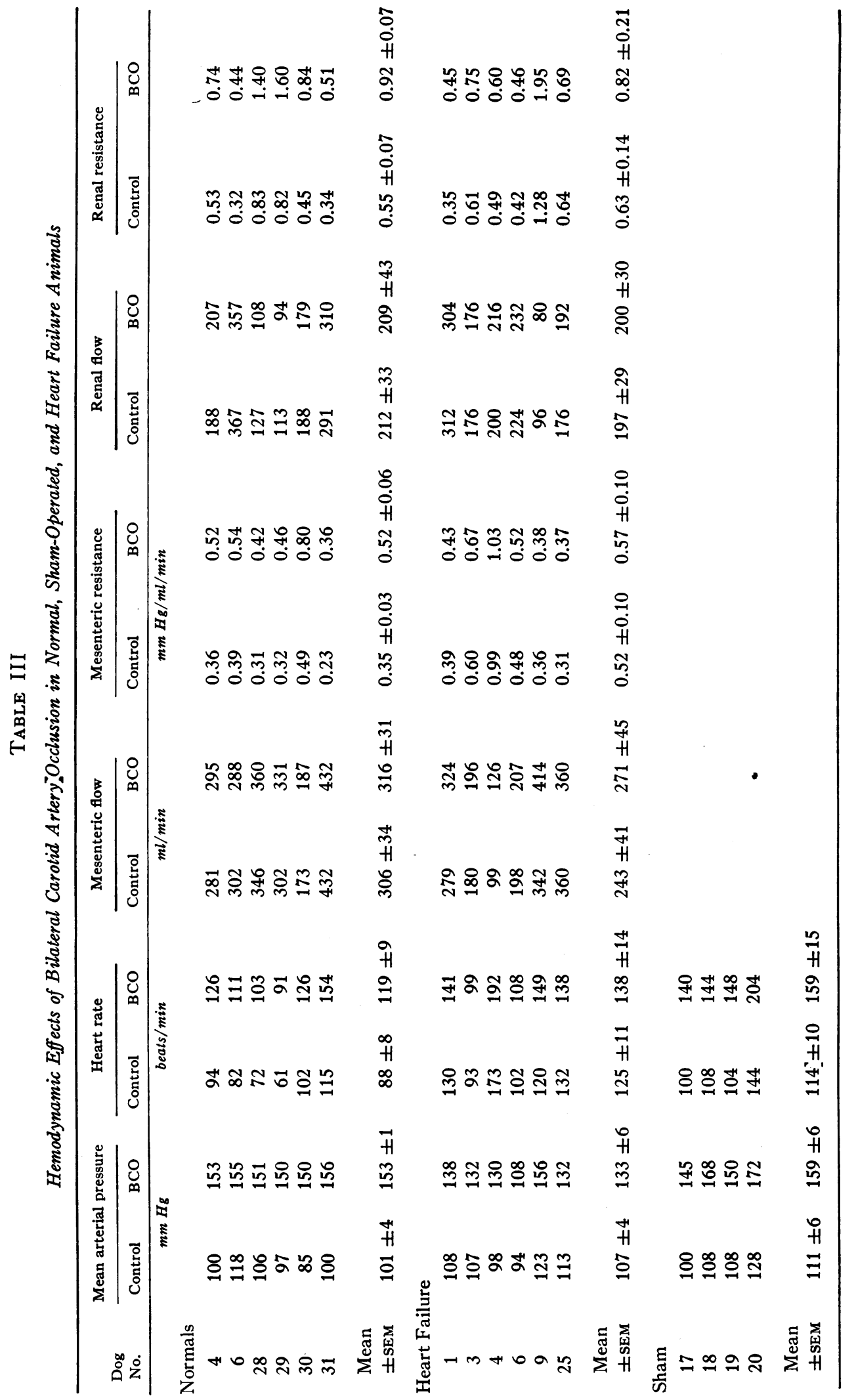



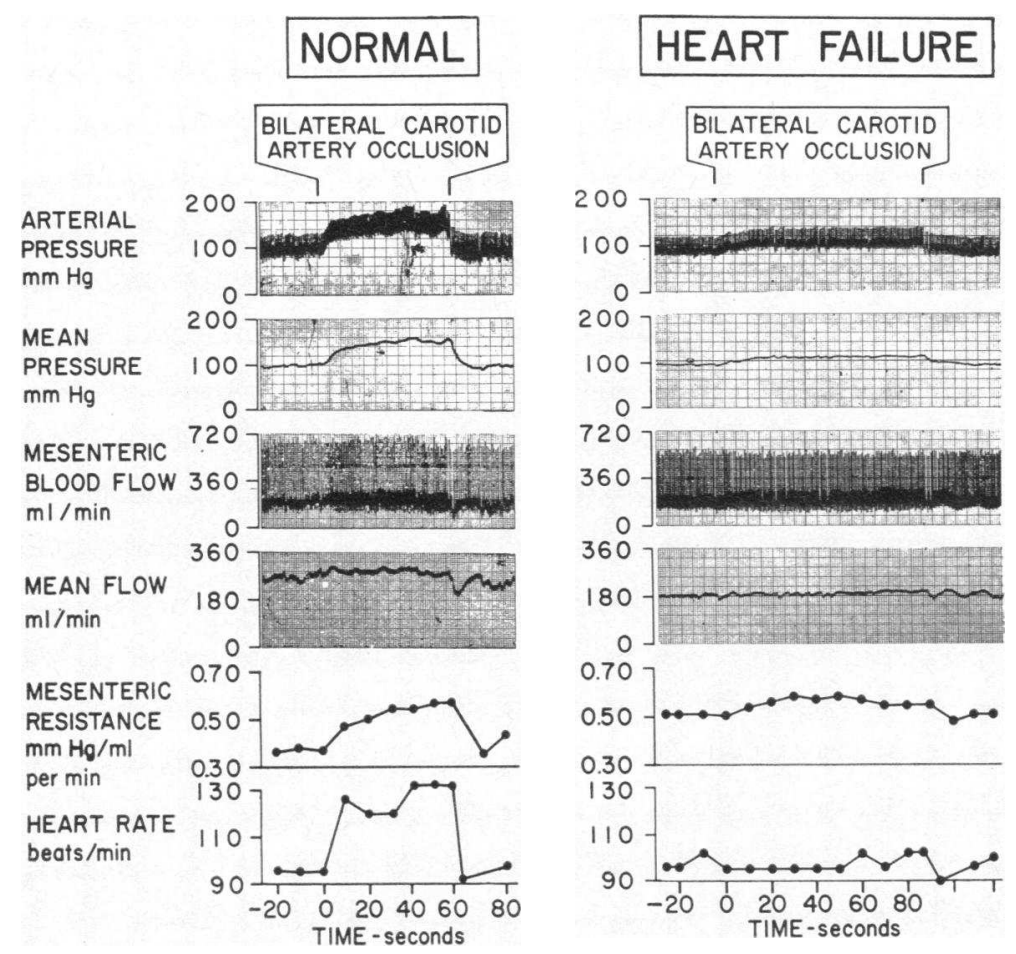

Figure 3 The effects of a prolonged period of bilateral carotid artery occlusion on mesenteric hemodynamics in the same dog in the normal state (left) and later in the heart failure state (right).

in man; resetting of the threshold without a change in sensitivity of the reflex has been produced by hypercapnia in normal subjects (24). In the present study the level of consciousness was constant and the $\mathrm{P}_{\mathrm{co}_{2}}$ levels were similar in normal dogs and those with heart failure (Table I).

In the present study, the rise in arterial pressure induced by 1-phenylephrine was similar among the various groups of animals. Thus, in comparison with normal dogs the animals with hypertrophy and heart failure displayed a profoundly attenuated reflex response to essentially identical stimuli.

Although base line heart rates were higher in the hypertrophy and failure groups, base line mean arterial pressures were comparable. The higher baseline heart rate cannot explain our observation of a reduced sensitivity of the reflex; on the contrary, it has been noted that with higher initial heart rates the magnitude of reflex slowing is actually enhanced $(16,20)$. The transient alterations in this reflex during exercise may be pertinent to our findings, since in both heart failure and during exercise heightened sympathetic tone is present $(10,25-27)$ and there is evidence that in states of high sympathetic tone there is a depression of parasympathetically mediated reflexes $(28,29)$. Both in the conscious $\operatorname{dog}(3,30)$ and $\operatorname{man}(3,19)$ in the normal and heart failure states the reflex slowing of the heart rate in response to the transient hypertension induced by 1 -phenylephrine is mediated predominantly by the parasympathetic nervous system.

The second portion of this study demonstrated that this dysfunction in the baroreceptor reflex in heart failure is not confined to the vagally mediated heart rate slowing consequent to baroreceptor hypertension, but is observed also in the reflex responses induced by baroreceptor hypotension. Specifically, the baroreceptor reflex responsiveness to hypotension as assessed by alterations in arterial pressure, heart rate and regional resistances during $\mathrm{BCO}$, was profoundly depressed. In this instance also the stimulus applied to the baroreceptors was comparable in the normal and heart failure groups, since both the base line arterial pressures and the decrease in arterial pressure in the area of the carotid sinus during $\mathrm{BCO}$ were very nearly equal in the two groups. The average base line heart rates and regional resistances tended to be higher in the heart failure group. However, it seems unlikely that these elevated average base line values contributed significantly to the attenuated response in the heart failure group, since in the subgroup of the dogs with heart failure that had base line heart rates and regional resistance within the normal range, the attenuated response characteristic of 
the heart failure group as a whole was observed. Thus, both in the subgroups of heart failure dogs with base line values comparable to normal dogs and in the heart failure group as a whole, the increases in arterial pressure, heart rate, and regional resistances were substantially less than in normal dogs (Fig. 3).

The reflex responsiveness to BCO was not tested in the dogs with right ventricular hypertrophy only and it is reasonable to expect some depression in the reflex responses to baroreceptor hypotension in that group as well. Indeed, the attenuated responses to baroreceptor hypotension may not be peculiar to the heart failure state and may be a consequence of a variety of cardiac diseases as was shown for the depressed response to baroreceptor hypertension in the present investigation and by Eckberg, Drabinsky, and Braunwald (19).

Although this study has demonstrated a markedly impaired baroreceptor reflex in response to both hypertension and hypotension in heart failure, no attempt has been made to define the mechanism responsible for this dysfunction. However, several circulatory derangements known to occur in congestive heart failure may contribute to this baroreceptor reflex dysfunction. On the afferent side of the reflex, Abráhám (31) has described degenerative changes in the receptor fibers as well as in the neurofibrillar end plates in the baroreceptors of the aortic arch and particularly in the carotid sinuses of patients with a variety of cardiovascular diseases, including heart failure. These histologic abnormalities suggest that an alteration in the baroreceptors themselves may be involved. In addition, it has been shown that both in hypertension and congestive heart failure, the sodium and water contents of the arterial wall are increased $(32,33)$. These increased sodium and water contents might be responsible for reducing the distensibility of the arterial wall in the area of the carotid sinus and consequently the extent of distortion of the baroreceptors during changes in intra-arterial pressure, thus reducing the sensitivity of the reflex.

Another site at which the reflex dysfunction might occur is in the central nervous system. Recent evidence suggests that the baroreceptor reflexes can be either facilitated or inhibited by activation of higher centers in the brain $(34,35)$. These findings prompt speculation upon the possibility of alterations in the extent of facilitation or inhibition in situations of circulatory stress, including heart failure. Indeed, there exists considerable evidence that in states of heightened sympathetic tone parasympathetically mediated reflexes are attenuated (28, 29). Since sympathetic tone is considerably accentuated in heart failure $(10,25)$, this mechanism may contribute to the attenuation of the vagally mediated cardiac slowing during transient hypertension.

On the efferent side of the reflex, there is evidence both for defects in sympathetic and parasympathetic nervous control of the heart. It is well established that cardiac norepinephrine stores are markedly depleted in man (25) and experimental animals (36) with heart failure, and this depletion diminishes the chronotropic and inotropic responses to stimulation of the stellate ganglion (37) in experimental animals and chronotropic responses to sympathetically mediated reflexes in man (38). This mechanism is undoubtedly operative to some extent in the attenuated chronotropic response to $\mathrm{BCO}$ in animals with heart failure in the present study who had associated depletion of cardiac norepinephrine stores. However, it is less likely that a defect in adrenergic transmission accounted for the less intense vasoconstriction in the regional circulatory beds after BCO, since normal norepinephrine stores have been found in the kidneys in animals with congestive heart failure (39) and augmented neurotransmitter activity was identified in the peripheral vascular bed of patients with congestive heart failure and cardiac norepinephrine depletion (40). A structural alteration in the peripheral arterioles due to increased sodium and water content in the vessel wall which has been implicated in the decreased capacity of peripheral vessels to respond to vasodilatory stimuli in heart failure $(41,42)$ might limit the capacity of the arterioles to respond to neurogenic vasoconstrictor stimuli as well.

The rises in mesenteric and renal resistances in the normal and heart failure groups during BCO may have been supported by autoregulatory responses to elevated arterial pressure (43). Since perfusion pressure increased substantially more in the group of normal animals, autoregulatory influence should have been more intense in the mesenteric and renal beds of normal dogs and may have contributed to the greater increase in resistance observed in them.

Recently, preliminary evidence from this laboratory has suggested defective cardiac parasympathetic control in heart disease (19). In these studies, there was considerably less cardiac acceleration in patients with heart disease after pharmacologic blockade of parasympathetic nerve fibers, suggesting diminished outflow of parasympathetic nerve impulses from the central nervous system, a defect in the response of the sinoatrial node to acetylcholine or a depletion of cardiac intraneuronal acetylcholine stores. A similar attenuation of the chronotropic responses to atropine in patients with heart disease is evident in the experiments reported by Jose and Taylor (44), and they attributed this finding to a depressed intrinsic heart rate associated with heart disease.

Regardless of the precise mechanism or mechanisms causing this abnormal baroreceptor reflex in heart failure, this defect represents the loss of one of the major control mechanisms which tends to adjust heart rate, 
cardiac output, arterial pressure, and the inotropic state of the heart to maintain circulatory homeostasis during acute stress. The diminished ability to alter central and peripheral circulatory function reflexly in heart failure, as indicated in this study, may impair the compensatory response to acute circulatory stresses in patients with congestive heart failure. This defective response to $\mathrm{BCO}$ may not be confined to heart failure since a similar subnormal pressor and heart rate response to $\mathrm{BCO}$ has been observed in dogs subjected to hemorrhagic hypotension (45). In addition, these animals also displayed attenuated chronotropic and inotropic responses to stimulation of the stellate ganglion (46). A preliminary report has also delineated an absence of the normal pressor and heart rate increments induced by head up tilting in patients soon after transmural myocardial infarction without congestive heart failure or hypotension (47).

\section{ACKNOWLEDGMENTS}

We appreciate the technical assistance of Richard Pavelec, David Hendrick, and Daniel McKown.

This work was supported by U. S. Public Health Service Grants HE 12373 and HE 13441.

\section{REFERENCES}

1. Heymans, C., and E. Neil. 1958. Reflexogenic Areas of the Cardiovascular System. Little, Brown and Co., Boston, Mass. 34-55, 77-88.

2. Bronk, D. W., and G. Stella. 1935. The response to steady pressures of single end organs in the isolated carotid sinus. Amer. J. Physiol. 110: 708.

3. Glick, G., and E. Braunwald. 1965. Relative roles of the sympathetic and parasympathetic nervous systems in the reflex control of heart rate. Circ. Res. 16: 363.

4. Sarnoff, S. J., J. P. Gilmore, S. K. Brockman, J. H. Mitchell, and R. J. Linden. 1960 Regulation of ventricular contractility by the carotid sinus: its effect on atrial and ventricular dynamics Circ. Res. 8: 1123.

5. Glick, G. 1971. Importance of the carotid sinus baroreceptors in the regulation of myocardial performance. J. Clin. Invest. 50: 1116.

6. Bond, R. F., and H. D. Green. 1969. Cardiac output redistribution during bilateral common carotid artery occlusion. Amer. J. Physiol. 216: 393.

7. Ross, J., C. J. Frahm, and E. Braunwald. 1961. Influence of carotid baroreceptors and vasoactive drugs on systemic vascular volume and venous distensibility. Circ. Res. 9: 75.

8. Vatner, S. F., D. Franklin, R. L. Van Citters, and E. Braunwald. 1970. Effects of carotid sinus nerve stimulation on blood flow distribution in conscious dogs at rest and during exercise. Circ. Res. 27: 495.

9. Epstein, S. E., G. D. Beiser, R. E. Goldstein, M. Stampfer, A. S. Wechsler, G. Glick, and E. Braunwald. 1969. Circulatory effects of electrical stimulation of the carotid sinus nerves in man. Circulation. 40: 269.

10. Gaffney, T. E., and E. Braunwald. 1963. Importance of adrenergic nervous system in support of circulatory function in patients with congestive heart failure. Amer. J. Med. $34: 320$.
11. Smyth, H. S., P. Sleight, and G. W. Pickering. 1969. Reflex regulation of arterial pressure during sleep in man: a quantitative method of assessing baroflex sensitivity. Circ. Res. $24: 109$.

12. Vatner, S. F., D. Franklin, and E. Braunwald. 1971. The effects of anesthesia and sleep on the circulatory response to carotid sinus nerve stimulation. Amer.J. Physiol. 220: 1249.

13. Bristow, J. A., C. Prys-Roberts, A. Fisher, T. G. Pickering, and P. Sleight. 1969. Effects of anesthesia on baroreflex control of heart rate in man. Anesthesiology. $31: 422$.

14. Barger, A. C., B. B. Roe, and G. S. Richardson. 1952. Relation of valvular lesions and of exercise to auricular pressure, work tolerance, and to the development of chronic, congestive failure in dogs. Amer. J. Physiol. $169: 384$.

15. Snedecor, G. W., and W. G. Cochran. 1969. Statistical Methods. The Iowa State University Press, Ames. 91$106,135-147,172-175$.

16. Warner, H. R., and A. Cox. 1962. A mathematical mode of heart rate control by sympathetic and vagus efferent information. J. Appl. Physiol. 17: 349.

17. Franklin, D. L., N. W. Watson, K. Pierson, and R. L. Van Citters. 1966. Technique for radiotelemetry of blood flow velocity from unrestrained animals. Amer. J. Med. Electron. 5: 24.

18. Vatner, S. F., D. Franklin, and R. L. Van Citters. 1970. Simultaneous comparison and calibration of the Doppler and electromagnetic flowmeters. J. Appl. Physiol. 29 : 907.

19. Eckberg, D. L., M. Drabinsky, and E. Braunwald. 1971. Defective cardiac parasympathetic control in patients with heart disease. N. Engl. J. Med. 285: 877.

20. Alexander, N., and M. DeCuir. 1966. Loss of baroreflex bradycardia in renal hypertensive rabbits. Circ. Res. 19: 18.

21. Bristow, J. D., J. Honour, G. W. Pickering, P. Sleight, and T. Smyth. 1969. Diminished baroreflex sensitivity in high blood pressure. Circulation. 39: 48.

22. Bristow, J. D., E. B. Brown, Jr., D. J. C. Cunningham, M. G. Howson, E. S. Peterson, G. W. Pickering, P. Sleight. 1971. Effect of bicycling on the baroreflex regulation of pulse interval. Circ. Res. 28: 582.

23. Eckberg, D. L., G. F. Fletcher, and E. Braunwald. 1972. Mechanism of prolongation of the R-R interval with electrical stimulation of the carotid sinus nerves in man. Circ. Res. 30: 131.

24. Bristow, J. D., E. B. Brown, D. J. C. Cunningham, R. D. Goode, M. G. Howson, and P. Sleight. 1971. The influence of ventilation, carbon dioxide, and hypoxia on the baroreceptor reflex in man. J. Physiol. (London). 216: 281.

25. Chidsey, C. A., E. Braunwald, and A. G. Morrow. 1965. Catecholamine excretion and cardiac stores of norepinephrine in congestive heart failure. Amer. $J$. Med. 39: 442.

26. Epstein, S. E., B. F. Robinson, R. L. Kahler, and E. Braunwald. 1965. Effects of beta adrenergic blockade on the cardiac response to maximal and submaximal exercise in man. J. Clin. Invest. 44: 1745.

27. Sonnenblick, E. H., E. Braunwald, J. F. William, Jr., and G. Glick. 1965. Effects of exercise on myocardial force-velocity relations in intact unanesthetized man: relative roles of changes in heart rate, sympathetic ac- 
tivity, and ventricular dimensions. J. Clin. Invest. 44: 2051.

28. Gellhorn, E. 1964. Cardiovascular reactions in asphyxia and the post-asphyxial state. Amer. Heart J. 67: 73 .

29. Gellhorn, E. 1964. The significance of the state of the central autonomic nervous system for quantitative and qualitative aspects of some cardiovascular reactions. Amer. Heart J. 67: 106.

30. Higgins, C. B., D. L. Eckberg, S. F. Vatner, and E. Braunwald. 1971. Alterations in the baroreceptor reflex in conscious dogs with congestive heart failure. Clin. Res. 19: 165 (Abstr.)

31. Abráhám, D. 1967. The structure of baroreceptors in pathological conditions in man. In Baroreceptors and Hypertension; Proceedings of an International Symposium. P. Kezdi, editor. Pergamon Press Ltd. Oxford. 273.

32. Tobian, L., Jr., and J. Binion. 1954. Artery wall electrolytes in renal and DCA hypertension. J. Clin. Invest. 33: 1407.

33. Zelis, R., C. S. Delea, H. N. Coleman, and D. T. Mason. 1970. Arterial sodium content in experimental congestive heart failure. Circulation. 41: 213.

34. Gebber, G. L., and D. W. Snyder. 1970. Hypothalamic control of baroreceptor reflexes. Amer. J. Physiol. 218: 124.

35. Klevans, L. R., and G. L. Gebber. 1970. Facilitatory forebrain influence on cardiac component of baroreceptor reflexes. Amer. J. Physiol. 219: 1235.

36. Chidsey, C. A., G. A. Kaiser, E. H. Sonnenblick, J. F. Spann, and E. Braunwald. 1964. Cardiac norepinephrine stores in experimental heart failure in the dog. J. Clin. Invest. 43: 2386.

37. Covell, J. W., C. A. Chidsey, and E. Braunwald. 1966. Reduction of the cardiac response to post-ganglionic sympathetic nerve stimulation in experiment heart failure. Circ. Res. 19: 51.

38. Beiser, G. D., S. E. Epstein, M. Stampfer, and R. E. Goldstein. 1968. Impaired heart rate response to sym- pathetic nerve stimulation in patients with cardiac decompensation. Circulation. 38: VI-40 (Abstr.)

39. Chidsey, C. A., and E. Braunwald. 1966. Sympathetic activity and neurotransmitter depletion in congestive heart failure. Pharmacol. Rev. 18: 685.

40. Kramer, R. S., D. T. Mason, and E. Braunwald. 1968. Augmented sympathetic neurotransmitter activity in the peripheral vascular bed of patients with congestive heart failure and cardiac norepinephrine depletion. Circulation. 38: 629.

41. Zelis, R. F., D. T. Mason, and E. Braunwald. 1968. A comparison of the effects of vasodilator stimuli on peripheral resistance vessels in normal subjects and in patients with congestive heart failure. J. Clin. Invest. 47: 960 .

42. Zelis, R., and D. T. Mason. 1970. Diminished forearm arteriolar dilator capacity produced by mineralocorticoidinduced salt retention in man: implications concerning congestive heart failure and vascular stiffness. Circulation. 41 : 589.

43. Johnson, P. C. 1964. Review of previous studies and current theories of autoregulation. Circ. Res. 15 (Suppl. I) : I-9.

44. Jose, A. D., and R. R. Taylor. 1969. Autonomic blockade by propranolol and atropine to study intrinsic myocardial function in man. J. Clin. Invest. 48: 2019.

45. Glaviano, V. V., and Y. Shiuntetsu. 1967. Cardiovascular effects of bilateral common carotid occlusion in hemorrhagic shock. In Baroreceptor and Hypertension; Proceedings of an International Symposium. P. Kezdi, editor. Pergamon Press Ltd. Oxford. 375.

46. Glaviano, V. V., and M. A. Klouda. 1965. Myocardial catecholamines and stimulation of the stellate ganglion in hemorrhagic shock. Amer. J. Physiol. 209: 751.

47. Hughes, J. L., E. H. Amsterdam, D. T. Mason, E. Mansour, and R. Zelis. 1971. Abnormal peripheral vascular dynamics in patients with acute myocardial infarction: diminished reflex arteriolar construction. Clin. Res. 19: 321. (Abstr.) 